\title{
PENYULUHAN PENGGUNAAN PUNGTUASIPADA KARYA TULIS SISWA KELAS XI IPAMADRASAH ALIYAHRAUDLATUSSHIBYAN NW BELENCONG GUNUNG SARI
}

\author{
Saharudin, Agus Saputra, Khusnul Khotimah, Arif Nasrullah, Rahmad Hidayat \\ Pendidikan Bahasa Indonesia, Universitas Mataram, sahrul_saharuddin@yahoo.com \\ Pendidikan Bahasa Inggris, Universitas Mataram, saputra.box@gmail.com \\ Pendidikan Bahasa Inggris, Universitas Mataram, khusnul_pena@yahoo.com \\ Pendidikan Agama, Universitas Mataram, me.nasrullah@gmail.com \\ Pendidikan Bahasa Indonesia, Universitas Mataram, asscouty456@gmail.com
}

\begin{abstract}
ABSTRAK
Abstrak: Kegiatan Penyuluhan Penggunaan Pungtuasi pada Karya Tulis Siswa Kelas XI IPA MA Raudlatusshibyan NW Belencong Gunung Sari dilaksanakan dengan dasar sering abainya penutur bahasa Indonesia terhadap aturan berbahasa Indonesia lisan dan tulis. Pengabaian aturan itu dilakukan secara sadar dan tidak sadar. Pengabaian aturan tidak hanya dilakukan oleh masyarakat awam, tetapi juga dilakukan oleh kaum terpelajar di lingkungan perguruan tinggi serta instansi-instansi pemerintah.

Kegiatan dilaksanakan di MA Raudlatusshibyan NW Belencong dengan melibatkan siswa kelas XI IPA. Kegiatan dilaksanakan dalam bentuk pemberian materi, diskusi, dan pemecahan masalah dalam bentuk soal-soal. Materi penyuluhan adalah penggunaan pungtuasi berdasarkan Pedoman Umum Ejaan Bahasa Indonesia sesuai dengan Permendikbud nomor 50 tahun 2015.

Kegiatan penyuluhan dapat dikatakan berhasil berdasarkan serapan peserta terhadap materi yang dibuktikan dengan kemampuan peserta dalam menyelesaikan persoalan yang diberikan. Peserta merasa kegiatan semacam ini penting karena membuat mereka sadar bahwa penggunaan pungtuasi yang mereka pahami sebelumnya masih terdapat banyak kekeliruan. Untuk itu, kegiatan semacam ini perlu digalakkan demi terjaganya bahasa Indonesia yang baik, terutama benar.
\end{abstract}

Kata Kunci: penyuluhan, penggunaan pungtuasi, karya tulis.

Abstract: Elucidation activity of Punctuation Usage on Student Writing Class XI IPA MA Raudlatusshibyan NW Belencong Gunung Sari is implemented on the basis of frequent Indonesian speakers' misuses on Indonesian oral and written rules. The ignorance of the rules is done consciously and unconsciously. The ignorance of rules is not only done by ordinary people, but also done by educated people in the environment of universities and government agencies.

The activity was held in MA Raudlatusshibyan NW Belencong by involving students of class XI IPA. Activities are carried out in the form of giving materials, discussion, and problem solving in the form of questions. The extension material is the use of punctuation based on the Spelling General Guidelines of Indonesia in accordance with Permendikbud number 50 of 2015.

This elucidation activity can be said to succeed based on participants' absorption of the material as evidenced by the ability of participants in solving the given problem. Participants feel this kind of activity is important because it makes them aware that the use of punctuations that they understand before there are still many mistakes. For that, this kind of activity should be encouraged in order to maintain good Indonesian usage.

Keywords:elucidation, punctuation usage, academic writing.

Riwayat Artikel: Diterima: 2 Desember 2017, Disetujui: 10 Januari 2018 


\section{A. PENDAHULUAN}

Keterampilan menulis secara umum merupakan keterampilan yang paling tinggi tingkatannya dibandingkan keterampilan berbicara, membaca, dan mendengar. Sukasmo (2012) menyatakan bahwa keterampilan menulis harus melalui latihan secara intensif dan tidak dapat diperoleh secara serta-merta tanpa latihan yang terus-menerus.

Seorang penulis tidak hanya melakukan proses berpikir, tetapi dia harus mampu mengorganisasi ide-ide atau gagasan yang diperoleh dari proses berpikir berdasarkan pengalaman yang diperoleh melalui kegiatan berbahasa yang lain (menyimak dan membaca), dengan menggunakan serangkaian simbol atau lambang dalam bentuk kalimat, paragraf, dan wacana, serta memperhatikan penggunaan ejaan yang tepat (Grabe, 1996). Semua syaratsyarat tersebut harus dilakukan terutama dalam menulis karya yang sifatnya ilmiah.

Penggunaan ejaan sebagai salah satu kemampuan yang harus dimiliki oleh seorang penulis karya ilmiah relatif sering diabaikan. Hal ini dapat disebabkan terlalu fokusnya seorang penulis dalam mentransformasikan pikiran dan idenya dalam bentuk tulisan. Kefokusan itu membuat seorang penulis lebih menitikberatkan kesempurnaan rangkaian kalimat daripada ketepatan penggunaan aturan ejaan. Salah satu aturan ejaan yang sering kurang diperhatikan adalah aturan penggunaan Pungtuasi.

Kekeliruan berupa abainya penggunaan pungtuasi yang benar sering dilakukan oleh berbagai kalangan terpelajar. Kalangan terpelajar yang dimaksud tidak hanya siswa, tetapi juga mahasiswa. Bahkan, kalangan pendidik pun tidak luput dari kekeliruan tersebut. Jika dibiarkan, lamakelamaan, kekeliruan semacam ini dapat menyebabkan banyak orang akan merasa dan memvonis apa yang biasa mereka tuliskan merupakan standar kebenaran.

Kenyataan semacam itu memerlukan langkah-langkah preventif dalam rangka menjaga penggunaan bahasa Indonesia yang baik dan benar. Langkah-langkah preventif itu dapat dilakukan dengan mengadakan penyuluhan dan pelatihan pada berbagai kalangan, utamanya siswa-siswi sekolah menengah atas. Penyuluhan tersebut nantinya dapat menjadi bekal mereka dalam meneruskan pendidikan ke jenjang perkuliahan. Hal ini mengingat jenjang perkuliahan akan benar-benar berkutat pada kegiatan tulis-menulis ilmiah.

Sebagaimana tersebut di atas, penyuluhan penggunaan pungtuasi terhadap siswa sekolah menengah atas penting dilakukan. Hal ini mengingat pada jenjang mahasiswa masih banyak ditemukan mahasiswa yang belum mampu menggunakan pungtuasi dengan tepat sebagaimana aturan yang berlaku -termasuk juga kemampuan merangkai kalimat dengan efektif untuk membentuk paragraf-. Untuk itulah, langkah preventif perlu dilakukan. 
Dalam pada itu, kurikulum sekolah menengah yang berlaku saat ini lebih menitikberatkan pembelajaran bahasa Indonesia yang berbasis pada teks. Para siswa diharapkan mampu menulis teks dengan benar sesuai dengan macam-macam teks yang termaktub dalam kurikulum. Kebenaran menulis teks tentu mensyaratkan perbagai hal sebagaimana yang telah disebutkan di atas. Oleh karena itu, penyuluhan penggunaan pungtuasi pada siswa-siswi sekolah menengah atas dalam kesempatan ini penting dilakukan sebagai langkah preventif dan mempersiapkan mereka ke jenjang berikutnya yang lebih kompleks.

Berbahasa Indonesia tulis yang baik dan terutama yang benar mengharuskan kita untuk taat kepada aturan-aturan berbahasa. Dalam rangka itu, bahasa Indonesia memiliki pelbagai aturan seperti aturan kebakuan, keefektifan kalimat, ejaan, dan semacamnya. Berbagai aturan itu disadari keberadaannya oleh para penutur bahasa Indonesia. Namun, pada praktisnya, aturan-aturan itu kadang diabaikan atau dianggap kurang penting. Kontradiksi ini dapat menimbulkan kebiasaan tidak taat terhadap aturan bahasa.

Di sisi yang lain, terdapat juga penutur bahasa yang tidak sadar akan keberadaan aturan berbahasa tulis yang harus ditaati. Penutur yang semacam ini biasanya mendasarkan diri pada standar keumuman yang biasa dilakukan oleh orang lain yang dilihatnya. Padahal, standar keumuman itu belum tentu benar atau taat asas. Kenyataan ini merupakan masalah yang lebih-lebih harus mendapat perhatian.

Berdasar pada kenyataan di atas, beberapa masalah yang dapat dirumuskan adalah sebagai berikut.

a. Penutur bahasa sadar akan adanya aturan dalam berbahasa tulis. Namun, penutur tersebut sering abai dan menganggap aturan tersebut kurang penting.

b. Penutur bahasa tidak sadar akan adanya aturan dalam berbahasa tulis sehingga tulisan yang dibuat hanya mementingkan aspek menuangkan pikiran dalam bentuk tulisan.

c. Penutur membuat aturan sendiri berdasarkan pengalaman visualnya melihat kebiasaan orang lain yang dianggapnya benar. Hal ini tentu dapat mengacaukan aturan-aturan baku yang sudah ditetapkan.

Kegiatan penyuluhan ini melibatkan siswa kelas XI IPA MA Raudlatusshibyan NW Belencong. Siswa sekolah menengah atas dipilih sebagai peserta penyuluhan agar dari sejak dini mereka memiliki kesadaran akan pentingnya memahami dan menaati aturan dalam menulis khususnya aturan penggunaan pungtuasi. Selain itu, peserta penyuluhan diharapkan memiliki bekal sejak dini untuk menghadapi jenjang pendidikan yang lebih tinggi. 


\section{B. METODE PELAKSANAAN}

Berdasarkan keadaan dan masalah yang telah dirumuskan sebelumnya, langkah-langkah pemecahan masalah yang dapat diambil sebagai berikut.

a. Penyuluh menekankan pentingnya berbahasa Indonesia yang baik dan benar serta pentingnya taat terhadap aturan berbahasa.

b. Penyuluh menyampaikan berbagai aturan-aturan yang berlaku dalam kegiatan tulis-menulis.

c. Penyuluh memberikan contoh karya tulis yang tidak menaati aturan penggunaan pungtuasi yang sesuai dengan Pedoman Umum Ejaan Bahasa Indonesia.

d. Penyuluh mengajak peserta untuk bersama-sama menganalisis dan menentukan kesalahan penggunaan pungtuasi.

e. Penyuluh mengajak peserta untuk membuat tulisan yang mengikuti aturan penggunaan pungtuasi.

f. Penyuluh memaparkan rangkuman hasil kegiatan yang telah dilakukan.

g. Penyuluh bersama peserta melakukan evaluasi dalam bentuk diskusi dan tanya jawab mengenai materi dan pelaksanaan kegiatan penyuluhan.

Metode yang digunakan dalam kegiatan penyuluhan ini disesuaikan dengan langkah-langkah pemecahan masalah. Berdasarkan langkah-langkah pemecahan masalah yang telah disebutkan sebelumnya, metode yang digunakan berupa metode ceramah, tanya jawab, diskusi, dan studi kasus.

Ceramah dilakukan dengan memberikan materi kepada peserta berupa aturan penggunaan pungtuasi. Tanya jawab dilakukan untuk memberikan kesempatan sebesar-besarnya kepada peserta untuk menggali pengetahuan dari penyuluh. Studi kasus dilaksanakan dalam bentuk kegiatan analisis dan menentukan pelbagai bentuk kesalahan penggunaan pungtuasi pada karya tulis yang siswa dan karya tulis yang telah disediakan oleh penyuluh. Pada akhirnya, penyuluh dan peserta bersama-sama membuat rangkuman mengenai proses dan hasil kegiatan dan melakukan evaluasi.

\section{HASIL DAN PEMBAHASAN}

Sebagaimana rumusan masalah dan kerangka pemecahan masalah yang telah ditetapkan, realisasi pemecahan masalah dilakukan dengan melaksanakan penyuluhan penggunaan pungtuasi pada siswa kelas XI IPA MA Raudlatusshibyan NW Belencong. Penyuluhan dilakukan dalam bentuk pemberian materi pungtuasi oleh para penyuluh dan diskusi berupa analisis kesalahan penggunaan pungtuasi serta tanya jawab seputar berbahasa Indonesia yang baik dan benar.

Pada tahap pertama, kepada peserta diberikan materi tentang penumbuhan sikap positif dan cinta terhadap bahasa Indonesia. Dalam pada itu, kepada peserta juga diberikan materi tentang hakikat berbahasa Indonesia yang baik dan benar. Pada tahap kedua, penyuluh menyampaikan 
materi inti mengenai penggunaan pungtuasi yang benar dalam menulis. Selanjutnya, kegiatan penyuluhan ditutup dengan diskusi antara penyuluh dan peserta mengenai analisis kesalahan penggunaan pungtuasi pada wacana tulis yang telah disediakan penyuluh.

\section{Analisis Evaluasi}

Kegiatan penyuluhan ini terlaksana sesuai dengan rencana yang telah disusun dengan sedemikian rupa. Terlaksananya kegiatan ini dengan baik tercapai atas kerja sama yang baik antara penyuluh dengan pihak sekolah MA Raudlatusshibyan NW Belencong dari masa persiapan sampai berakhirnya kegiatan. Pihak sekolah sangat membantu pelaksanaan kegiatan dalam bentuk menyiapkan ruang kelas dan peralatan penyuluhan lain yang dibutuhkan.

Kegiatan penyuluhan dilaksanakan dengan diawali upacara pembukaan yang dibuka langsung oleh Kepala Sekolah MA Raudlatusshibyan NW Belencong. Setelah dibuka, peserta diberikan ice breaking dan tes awal mengenai materi untuk mengetahui kemampuan peserta.

Kegiatan ini, atas pengakuan kedua belah pihak, dinyatakan berhasil atau terlaksana dengan baik. Pihak sekolah yang diwakili oleh sekolah merasa terbantu atas terselenggaranya kegiatan penyuluhan semacam ini. Pihak sekolah juga berharap agar kegiatan semacam ini juga dilaksanakan untuk guru sekolah dengan level materi yang lebih tinggi. Harapan tersebut disampaikan mengingat para guru sekarang ini lebih banyak dituntut untuk menulis karya ilmiah.

Para peserta cukup aktif dalam menerima materi yang disampaikan oleh penyuluh. Peserta juga senang mendapat materi penggunaan pungtuasi dalam menulis. Mereka merasa terbantu dan menjadi lebih paham seluk-beluk penggunaan pungtuasi yang selama ini penggunaannya masih rancu menurut pengakuan mereka. Peserta juga sangat antusias ketika diberikan soal oleh penyuluh berupa kalimat-kalimat yang tidak menggunakan pungtuasi dengan benar.

Tersampaikannya materi kepada peserta dapat terlihat dari kemampuan peserta dalam menjawab soal-soal yang diberikan penyuluh, baik dalam proses penyampaian materi maupun pada tahapan tes akhir (lihat lampiran). Soal-soal ini diberikan sebagai tes akhir untuk mengetahui serapan peserta terhadap materi yang diberikan. Berdasarkan jawaban peserta, materi dapat dikatakan tersampaikan dengan baik. Hal ini juga didukung oleh antusiasme peserta yang secara aktif berdiskusi dalam menyelesaikan soal-soal yang diberikan.

\section{Faktor Penghambat}

Faktor penghambat tidak dirasakan dari masa persiapan hingga berakhirnya kegiatan ini. Koordinasi yang baik antarpelaksana/penyuluh, 
sambutan yang baik dari pihak sekolah dan peserta, serta kerja sama antara pihak penyuluh dengan pihak sekolah membuat kegiatan berlangsung dengan baik dan sesuai rencana yang telah disusun sebelumnya.

\section{Faktor Pendukung}

Faktor pendukung terlaksananya kegiatan ini dengan baik adalah sebagai berikut.

a. Dukungan pemberian izin yang cepat dan dukungan moral dari pihak kampus Universitas Mataram. Pihak-pihak yang dimaksud yakni Rektor Universitas Mataram, LPPM Universitas Mataram, Ketua UPT MKU Universitas Mataram, dan Staf UPT MKU Universitas Mataram.

b. Sambutan yang baik dan bantuan peralatan oleh Kepala Sekolah MA Raudlatusshibyan NW Belencong dari tahap koordinasi hingga terselenggaranya kegiatan.

c. Kerja sama dan koordinasi yang baik dari pelaksana/penyuluh kegiatan.

\section{SIMPULAN DAN SARAN}

Berdasarkan rumusan masalah, kegiatan Penyuluhan Penggunaan Pungtuasi pada Karya Tulis Siswa Kelas XI IPA MA Raudlatusshibyan NW Belencong dapat disimpulkan sebagai berikut.

a. Kegiatan Penyuluhan Penggunaan Pungtuasi pada Karya Tulis Siswa Kelas XI IPA MA Raudlatusshibyan NW Belencong dilaksanakan pada hari Kamis, tanggal 26 Januari 2017, bertempat di ruang kelas XI IPA MA Raudlatusshibyan NW Belencong. Peserta kegiatan ini adalah siswa kelas XI IPA MA Raudlatusshibyan NW Belencong.

b. Pelaksanaan kegiatan sesuai dengan rencana yang telah disusun sebelumnya. Kegiatan terlaksana dengan baik atas kerja sama yang baik antara pihak penyuluh/pelaksana dengan pihak MA Raudlatusshibyan NW Belencong. Peserta dikatakan dapat menerima materi dengan baik dan sangat antusias berdasarkan jawaban peserta terhadap soal-soal yang diberikan.

c. Materi-materi kegiatan ini berupa aturan penggunaan pungtuasi yang terdapat di dalam Pedoman Umum Ejaan Bahasa Indonesia berdasarkan Permendikbud nomor 50 tahun 2015. Selain materi inti, peserta juga diberikan materi mengenai bahasa Indonesia yang baik dan benar.

d. Kegiatan penyuluhan dilaksanakan dengan menggunakan metode ceramah, diskusi, dan pemecahan masalah. 
Pada masa kini, penggunaan bahasa Indonesia yang baik dan benar, baik lisan maupun tulisan, relatif sering diabaikan. Pengabaian itu tidak hanya dilakukan oleh masyarakat yang awam, tetapi juga para kaum terpelajar yang berkecimpung di perguruan tinggi. Untuk itu, sosialisasi mengenai aturan berbahasa Indonesia lisan dan tulis harus digalakkan di mana pun dan kepada siapa pun.

\section{UCAPAN TERIMA KASIH}

Tim penulis mengucapkan terima kasih kepada Rektor Universitas Mataram, Ketua LPPM Universitas Mataram, Ketua UPT MKU Univeritas Mataram, Kepala MA Raudlatusshibyan NW Belencong Gunung Sari, Semua pihak lain yang terlibat dan tidak sempat disampaikan dalam kesempatan ini.

Akhirnya, kami berharap kegiatan ini dapat bermanfaat bagi banyak pihak dan dapat dilakukan secara berkesinambungan ke depannya demi terwujudnya penggunaan bahasa Indonesia yang baik dan benar

\section{DAFTAR RUJUKAN}

Tim Pengembang Pedoman Bahasa Indonesia. Pedoman Umum Ejaan Bahasa Indonesia. Jakarta: 2016.

\section{DOKUMENTASI KEGIATAN}

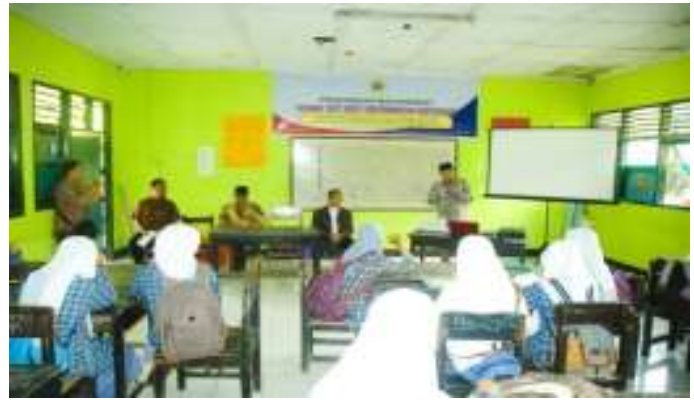

Pembukaan kegiatan oleh Kepala Sekolah

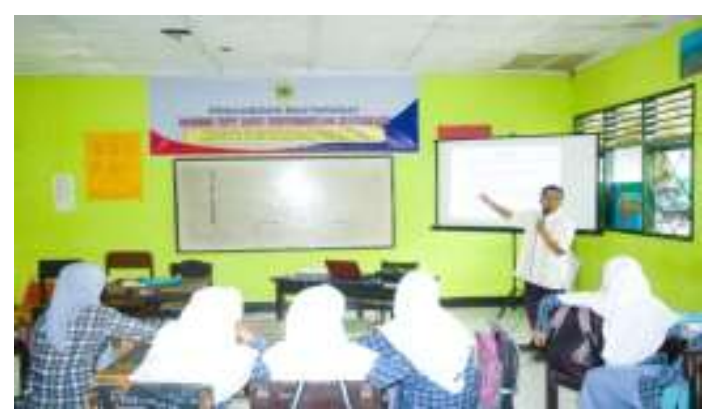

Proses penyuluhan oleh salah satu pemateri

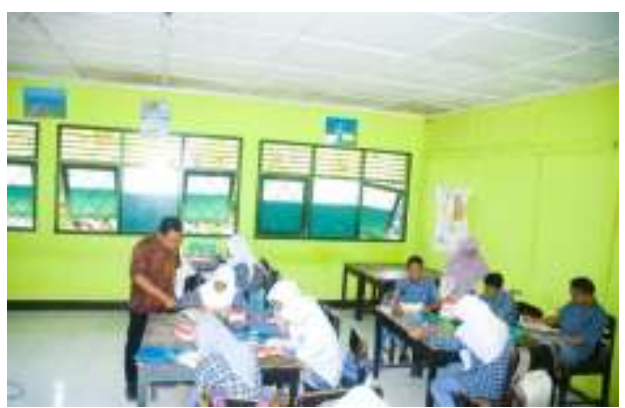

Suasana simulasi

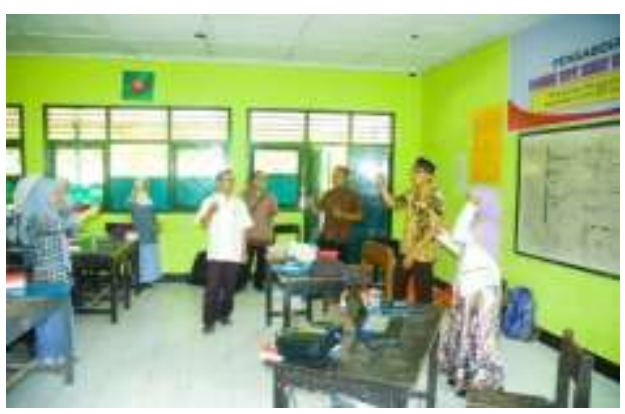

Ice breaking dengan senam otak 